\title{
Non-alcoholic Fatty Liver Disease: A Clinical Update
}

\author{
Joseph M Pappachan*1, Shithu Babu ${ }^{2}$, Babu Krishnan ${ }^{3}$ and Nishal C Ravindran ${ }^{4}$ \\ ${ }^{1}$ Department of Endocrinology, Diabetes \& Metabolism, Royal Lancaster Infirmary, University Hospitals of Morecambe Bay NHS \\ Trust, Lancaster, UK; ${ }^{2}$ Department of Medicine, Dorset County Hospital, Dorchester, UK; ${ }^{3}$ Department of Gastroenterology \& \\ Hepatology, Royal Bournemouth Hospital, Bournemouth, UK; ${ }^{4}$ Department of Gastroenterology \& Hepatology, Hinchingbrooke \\ Hospital, Hinchingbrooke, Huntingdon, UK
}

\begin{abstract}
Non-alcoholic fatty liver disease (NAFLD) is currently the most common chronic liver disease in developed countries because of the obesity epidemic. The disease increases liverrelated morbidity and mortality, and often increases the risk for other comorbidities, such as type 2 diabetes and cardiovascular disease. Insulin resistance related to metabolic syndrome is the main pathogenic trigger that, in association with adverse genetic, humoral, hormonal and lifestyle factors, precipitates development of NAFLD. Biochemical markers and radiological imaging, along with liver biopsy in selected cases, help in diagnosis and prognostication. Intense lifestyle changes aiming at weight loss are the main therapeutic intervention to manage cases. Insulin sensitizers, antioxidants, lipid lowering agents, incretin-based drugs, weight loss medications, bariatric surgery and liver transplantation may be necessary for management in some cases along with lifestyle measures. This review summarizes the latest evidence on the epidemiology, natural history, pathogenesis, diagnosis and management of NAFLD.
\end{abstract}

Citation of this article: Pappachan JM, Babu S, Krishnan B, Ravindran NC. Non-alcoholic fatty liver disease: A clinical update. J Clin Transl Hepatol 2017;5(4):384-393. doi: 10. 14218/JCTH.2017.00013.

\section{Epidemiology}

Non-alcoholic fatty liver disease (NAFLD) has emerged as the most prevalent chronic liver disease in developed nations in recent years. It is defined as the presence of $\geq 5 \%$ steatosis in the absence of secondary causes of fat accumulation in the

Keywords: Nonalcoholic fatty liver disease (NAFLD); Nonalcoholic steatohepatitis; $\mathrm{NASH}$; Insulin resistance; Metabolic syndrome; Lifestyle interventions; Bariatric surgery.

Abbreviations: ALT, alanine aminotransferase; AST, aspartate transaminase; CT, computed tomography; DPP-4, dipeptidyl peptidase-4; FXR, farnesoid X receptor; GLP-1, glucagon-like insulinotropic peptide-1; HDL, high density lipoprotein; HCC hepatocellular carcinoma; IR, insulin resistance; LDL, low density lipoprotein; MRI magnetic resonance imaging; MS, metabolic syndrome; NAFLD, nonalcoholic fatty liver disease; NAS, NAFLD activity score; NASH, nonalcoholic steatohepatitis; NFS, NAFLD fibrosis score; OCA, obeticholic acid; PCSK9, proprotein convertase subtilisin/kexin type 9; PPAR, peroxisome proliferator activated receptor; RCT, randomized control trial; SAF score, steatosis, inflammatory activity and fibrosis score; T2DM, type 2 diabetes mellitus; TE, Transient elastography; VLDL, very low density lipoprotein.

Received: 24 February 2017; Revised: 31 May 2017; Accepted: 24 June 2017

*Correspondence to: Dr. Joseph M Pappachan, Department of Endocrinology, Diabetes \& Metabolism, Royal Lancaster Infirmary, University Hospitals of Morecambe Bay NHS Trust, Lancaster, LA1 4RP, UK. E-mail: drpappachan@yahoo.co.in liver (described below). Prevalence of NAFLD is growing, even in the developing world, because of the global obesity epidemic. Moreover, very close association between the disease and metabolic syndrome has been identified.

Epidemiological data shows the global prevalence of NAFLD in different populations as follows: United States $30 \%$, Middle East - 32\%, South America - 30\%, Asia - 27\%, Europe $-24 \%$ and Africa $-13 \% .{ }^{1}$ Wide variations in the prevalence have also been identified among different ethnic groups of these populations. Another interesting trend noted is the increasing prevalence of NAFLD among paediatric age groups. Autopsy-based data showed that NAFLD prevalence among children aged 2-19 years to be $9.6 \%$ after adjustment for age, sex, race and ethnicity, and up to $38 \%$ in obese children. ${ }^{2}$

The disease starts with fatty liver or hepatic steatosis and may progress to steatohepatitis with hepatic inflammation. Five to twenty percent of patients with fatty liver develop nonalcoholic steatohepatitis (NASH) in their clinical course, of which $10-20 \%$ develop into higher-grade fibrosis and $<5 \%$ progress to full-blown cirrhosis. ${ }^{3}$ The prevalence of NASH may be underestimated, as the diagnosis requires histological confirmation. It is considered that at least $5 \%$ of the population may have NASH. ${ }^{4}$ Prevalence of NAFLD among the at-risk group is even higher.

Eighteen to thirty-three percent of cases with NAFLD were found to have type 2 diabetes mellitus (T2DM), and up to $66-83 \%$ of NAFLD cases were identified with markers of insulin resistance (IR). ${ }^{5-7}$ Even without a significant degree of dyslipidaemia, increasing levels of low-density lipoprotein cholesterol (LDL) levels (ranging from $<2.0 \mathrm{mmol} / \mathrm{L}$ to $2.7 \mathrm{mmol} / \mathrm{L}$ ) increased the prevalence of NAFLD from $19 \%$ to $42 \%$ in patients in a recent study. ${ }^{8}$ Prevalence of NAFLD also increases with age (up to $46 \%$ ), with the older age groups having higher mortality rates. ${ }^{9,10}$

\section{Natural history}

The natural history of NAFLD is not well established, with significant knowledge gaps about the marked inter-individual variations in disease onset, progression, and complications. NAFLD represents a wide spectrum of clinical entities from asymptomatic hepatic steatosis to more advanced liver disease with hepatic failure or hepatocellular carcinoma (HCC). ${ }^{1,11,12}$ The rate of disease progression in most cases is slow, although rapid development of advanced liver disease may be occasionally found. About one-third of people eventually develop $\mathrm{NASH}_{;}^{1,11,12}$ however, regression of fibrosis is also noticed in about $20 \%$ of these cases. ${ }^{12,13}$ 
Although increased cardiovascular mortality rate has been demonstrated in patients with NAFLD compared to general population, ${ }^{14}$ it is difficult to predict the risk for all-cause mortality in the absence of large population-based epidemiological study data. However, NASH was associated with a three-fold increase in liver-related mortality compared to the general population. ${ }^{15}$ Although NAFLD-associated cirrhosis was previously considered to have a higher risk for the development of HCC, recent evidence showed that up to $50 \%$ of patients with NAFLD-associated HCC did not have cirrhosis. ${ }^{15,16}$ Co-existent T2DM and obesity further increase risk of developing $\mathrm{HCC}$ in patients with NAFLD. ${ }^{17}$

\section{Pathogenesis}

NAFLD is considered as a metabolic disorder that results from complex interaction between genetic, hormonal and nutritional factors. ${ }^{1}$ Recent evidence suggests that several genetic risk factors predispose to the development and progression of NAFLD. ${ }^{18}$ For example, polymorphisms of PNPLA3, TM6SF2, FTO, LIPA, IFN 4 HFE, and HMOX-1 genes have been found to be associated with development/progression of the disease.

Obesity and metabolic syndrome (MS) are the most important risk factors identified in the development of NAFLD, and diabetes mellitus and hypertension are also linked to greater progression of the disease. ${ }^{19,20}$ Because of the similarity in pathogenesis -IR leading to hyperinsulinemia and gross alterations in carbohydrate and fat metabolism NAFLD and T2DM often co-exist in many individuals with metabolic syndrome. Moreover, both the disorders modify the risk for each other in a vicious circle. ${ }^{21}$ Full-blown T2DM also contributes to further worsening of hepatic steatosis and progression of established $\mathrm{NASH}$, fibrosis and cirrhosis, with a higher risk of development of HCC. ${ }^{20,21}$

Hyperinsulinemia and IR lead to increased adipocyte lipolysis and circulating free fatty acids (FFAs) that are taken up by hepatocytes, initiating various complex metabolic pathways that lead to NAFLD (Fig. 1). ${ }^{22}$ Because of the very strong association with MS, NAFLD is considered as the hepatic component of MS. ${ }^{20,22}$ Systemic IR reduces plasma adiponectin (an adipokine that increases insulin sensitivity and reduces inflammation) levels and increases the concentration of leptin (a cytokine secreted by adipocytes that plays a role in reducing body weight and fat mass). Reduced adiponectin levels ${ }^{23}$ and increased leptin levels (possibly from leptin resistance) $)^{24}$ are observed in patients with NAFLD. ${ }^{22}$

Adipose tissue lipolysis continues, even with hyperinsulinemia, because of the IR that results in increased plasma FFA concentration. Liver takes up the FFA in circulation, that if not oxidised gets stored in the liver in various forms or exported as very low density lipoproteins (VLDLs), as shown in the figure. High hepatic VLDL output also results in high circulating triglycerides and LDL and low circulating high density lipoprotein (HDL) levels that increase atherosclerosis risk. ${ }^{25}$

Increased glucagon levels with altered insulin/glucagon ratio is seen in patients with NAFLD. ${ }^{22}$ This promotes hepatic de novo lipogenesis (DNL), glycogenolysis and gluconeogenesis with higher hepatic glucose production and IR. Several gastrointestinal hormones and adipokines that regulate glucose and lipid metabolism, along with hormones controlling appetite and satiety, are also thought to contribute to the pathogenesis of NAFLD. ${ }^{1,20-22}$ Glucagon-like insulinotropic peptide-1 (GLP-1), ghrelin, selenoprotein P, leptin, adiponectin and the myokine - irisin - are some of these chemicals. ${ }^{22}$
As in the case of T2DM, the predominant risk factor for development of NAFLD is IR because of overweight/obesity that result from adverse lifestyle factors, such as overnutrition and physical inactivity. Although the majority of cases with NAFLD are obese/overweight individuals, a small but significant proportion of patients with the disease are lean. This phenomenon is especially common in the nonCaucasian populations, accounting for about $20 \%$ of cases. ${ }^{26}$

Predominant visceral obesity rather than generalized obesity, high dietary intake of fructose and cholesterol, and genetic risk factors may predispose to non-obese NAFLD. ${ }^{27}$ Higher rates of the mutant PNPLA3 gene variants and reduced serum adiponectin concentrations were reported in Caucasians with lean NAFLD compared to controls in a recent report. ${ }^{28}$ Potential roles of various lysophosphatidylcholines, phosphatidylcholines, lysine, tyrosine and valine were revealed in these cases using metabolomics studies.

Physical activity stimulates production of various soluble chemicals from muscle fibres, collectively termed as myokines, that show auto, para and endocrine functions. ${ }^{29,30}$ These myokines function as messengers between skeletal muscle and other tissues, such as liver, adipose tissue, heart, brain and blood vessels, signalling cascades of neurohormonal changes that modulate energy balance, metabolism and homeostasis. Although several myokines are described that may alter human metabolism, irisin is the most studied one among them. Physical activity increases irisin levels, leading to thermogenesis with a possible protective effect on metabolic disorders. ${ }^{31}$ However, there are studies showing increased levels of irisin in patients with metabolic syndrome and NAFLD. ${ }^{32,33}$

Acute response to exercise is shown to involve an increase in plasma irisin levels, whereas chronic exercise leads to reduction of the levels. ${ }^{34}$ Therefore, these conflicting reports on the plasma levels and metabolic effects of irisin may be related to development of resistance to the hormone or its effectors at tissue level that should be elucidated in future research. With the available evidence, we can conclude that by modulation of multiple metabolic parameters and the effects on body energy homeostasis, irisin may alter the risks for obesity, T2DM, NAFLD and cardiovascular disease. ${ }^{30,35}$

Alterations in the functions and composition of gut microbiome, otherwise known as intestinal dysbiosis, have been found to associated with obesity and its consequent metabolic disorders, including NAFLD, in animal models. ${ }^{36}$ Several subsequent studies in animal models and humans revealed clear association between gut dysbiosis and NAFLD. ${ }^{37-40}$ Even the degree of intestinal dysbiosis has been found to be correlated to the severity of NAFLD and the fibrosis. ${ }^{41}$ Several local and systemic factors, such as disruption of gastrointestinal mechanical barrier function, ${ }^{42}$ inflammation, ${ }^{38,43}$ various metabolites released by intestinal microbial metabolism/ actions, $^{44-46}$ and ethanol production by the microbiota ${ }^{39,47}$ were proposed as the potential pathogenic mechanisms.

Fig. 2 summarizes the pathogenesis of NAFLD and the potential therapeutic targets.

\section{Diagnosis}

NAFLD remains asymptomatic in a significant proportion of patients, and the diagnosis is often suspected when liver functions are found abnormal on biochemical testing or hepatic imaging (ultrasonography, computed tomography [CT] or magnetic resonance imaging [MRI] of liver) suggest 


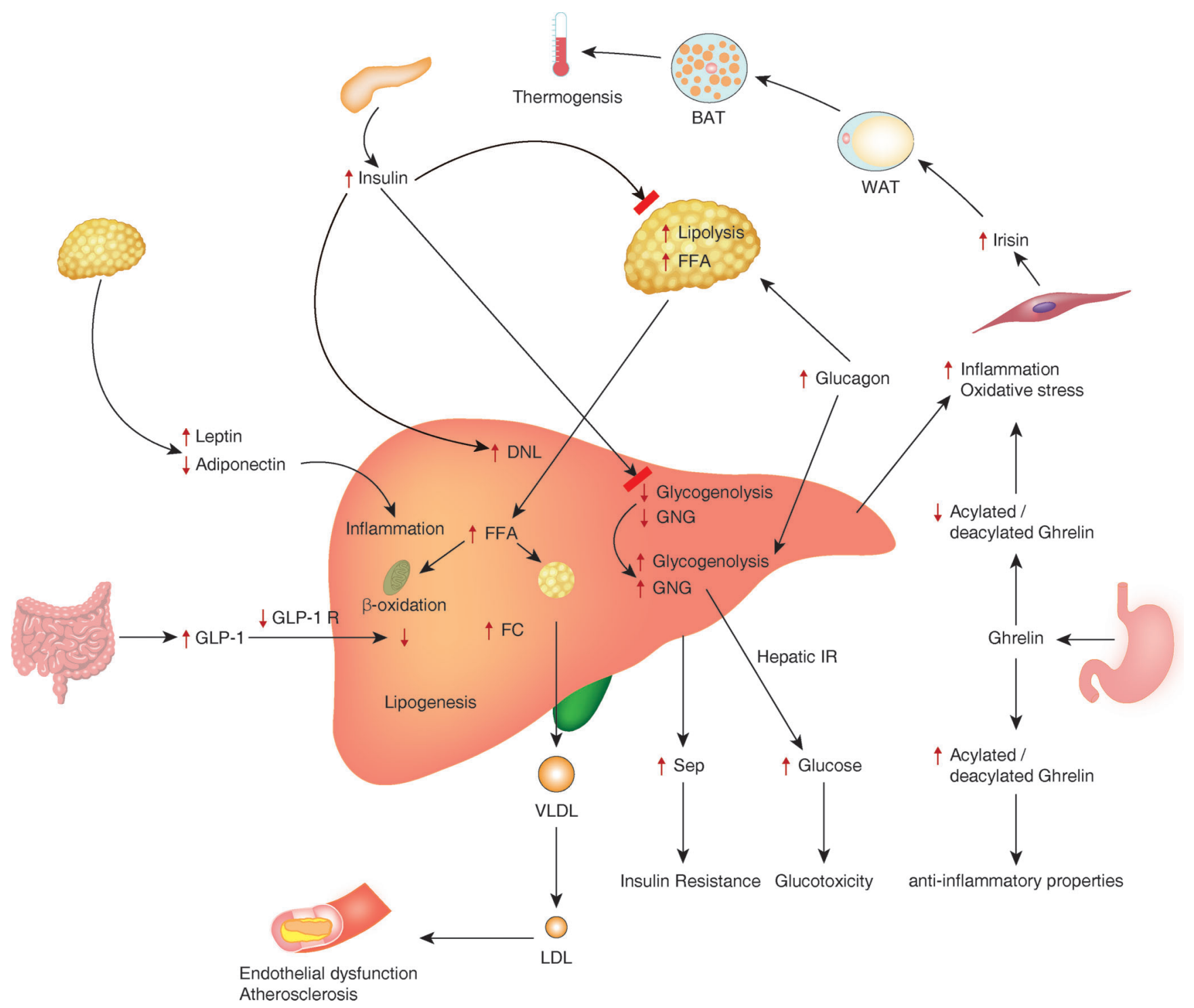

Fig. 1. Pathophysiological mechanisms involved in the development and complications of nonalcoholic fatty liver disease (NAFLD). BAT, brown adipose tissue; DNL, de novo lipogenesis; FC, free cholesterol; FFA, free fatty acid; GLP-1, glucagon-like insulinotropic peptide; GNG, gluconeogenesis; IR, insulin resistance; LDL, low density lipoprotein; SeP, selenoprotein P; VLDL, very low density lipoprotein; WAT, white adipose tissue. Figure reproduced with permission from Petta et al. ${ }^{22}$

fatty liver, when performed for some other reasons. The diagnosis of NAFLD is established when $\geq 5 \%$ of the hepatocytes show steatosis in the absence of causes for secondary steatosis, such as excessive alcohol consumption ( $>20$ grams/day in females and 30 grams/day in males) or chronic liver conditions associated with steatosis (viral, autoimmune, metabolic and toxic disorders). ${ }^{1,48,49}$

\section{Biochemical markers}

Liver enzymes can often be normal in a number of patients with NAFLD. For example, alanine aminotransferase (ALT) can be normal in up to $60 \%$ of patients with $\mathrm{NASH}$, and $53 \%$ of patients with high ALT had no evidence of NASH and advanced fibrosis. ${ }^{50,51}$ Although several biochemical markers, such as TNF- $\alpha$, IL-6, CRP, Pantraxin, Ferritin, serum prolidase enzyme activity, soluble receptor for advanced glycation end product and cytokeratin-18, have been proposed as useful in predicting the severity of NAFLD/NASH in the past, none of these markers have shown sufficient sensitivity or specificity for routine clinical application for diagnosis. ${ }^{52}$

NAFLD fibrosis score (NFS) using clinical and biochemical parameters to predict the severity of liver involvement is the most validated non-invasive tool to assess the disease. NFS is based on age, body mass index, aspartate transaminase (AST), ALT, platelets, albumin, and presence or absence of impaired fasting glucose. ${ }^{1}$ A low cut-off score $<1.455$ excludes advanced fibrosis with a negative predictive value of $93 \%$, while a high cut-off value exceeding 0.676 suggests advanced fibrosis with a positive predictive value of $90 \% .{ }^{1,53}$ Although the specificity of NFS is good, the sensitivity was recently reported as being low. ${ }^{54}$ 


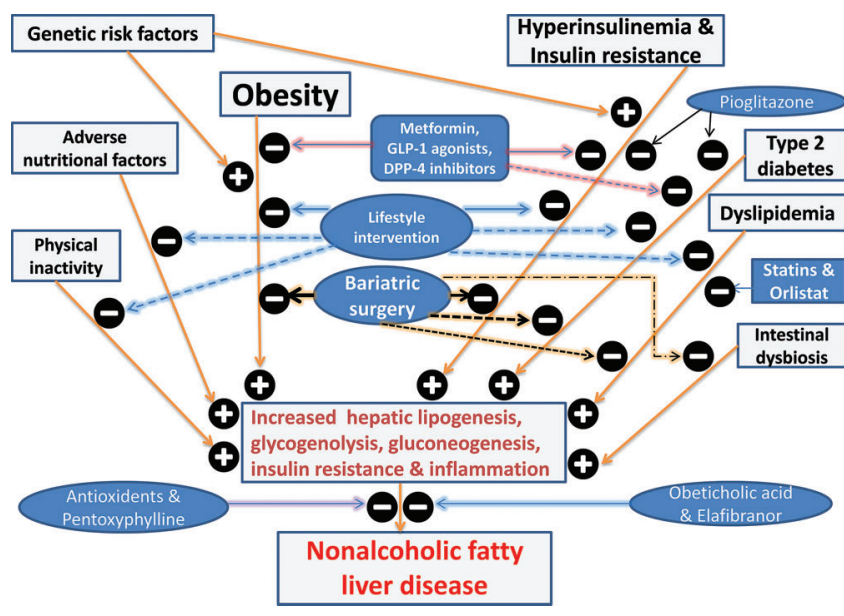

Fig. 2. Pathogenesis of nonalcoholic fatty liver disease and effects of various therapeutic interventions. $\mathcal{A}$ indicates positive effect and $\boldsymbol{Q}$ indicates negative effect.

\section{Radiological diagnosis}

Ultrasonography, CT and MRI of the liver are the standard imaging modalities used in clinical practice for diagnosis of NAFLD. In general, about $30 \%$ of liver steatosis should be present for these techniques to detect NAFLD. ${ }^{1,20,48}$ Ultrasonography is cheap, available easily and easy to perform, even from the bedside. The reported sensitivity of the test is $>90 \%$ in experienced hands when hepatic steatosis is $>30 \%$, although the sensitivity is much lower at lower degrees of steatosis. ${ }^{55,56}$ However, ultrasonography is highly operatordependent and, therefore, results can vary widely depending on the performer.

Transient elastography (TE) is an ultrasound-based imaging technique to detect the degree of fibrosis in patients with NAFLD and NASH. Sensitivity and specificity of TE to diagnose various stages of fibrosis have been reported to be $79-92 \%$ and $75-92 \%$ respectively. ${ }^{57}$ Recent evidence also suggests that ultrasound-based controlled attenuation parameter value used in the TE technique can predict the degree of steatosis in patients with NAFLD. ${ }^{58}$

CT scan is reported to be highly sensitive in quantifying the hepatic and visceral fat to measure the degree of adiposity in patients with metabolic syndrome and NAFLD. ${ }^{59}$ However, the test is expensive and associated with risk of radiation, and, therefore, not usually recommended in clinical settings. MRI is highly sensitive and specific for both quantitative and qualitative assessment of NAFLD. Newer MRI techniques, such as MR elastography, proton density fat fraction and the FerriScan method, can stage the degree of fibrosis non-invasively to diagnose and assess the prognosis of patients with NAFLD. ${ }^{59}$ However, these techniques are expensive and available only in specialized centres.

\section{Liver biopsy and histology}

Liver biopsy remains the gold standard for diagnostic evaluation of NAFLD. Biopsy not only confirms the diagnosis but provides information on extent of fibrosis and steatosis, necro-inflammation, and architectural distortion. In the past, the NASH Clinical Research Network histological scoring system was the widely used histological scoring system, representing a validated scoring system that generates a NAFLD activity score (NAS). A NAS score of 5 or $>5$ is considered NASH and $<3$ is not NASH. ${ }^{60}$

However, recent evidence suggests that NAS score cannot be used as a surrogate for discrimination between NASH and NAFLD, although it is useful for the histological diagnosis. ${ }^{61,62}$ Therefore, the European Association for the Study of liver recommends NAS for evaluation of the disease activity, and not for the diagnosis. The steatosis, inflammatory activity and fibrosis (SAF) score introduced in 2012, provides a reliable and reproducible measure for the diagnosis, grading and staging of NAFLD without much inter-observer variability. ${ }^{63}$ SAF score assesses both and separately the grade of steatosis $(S)$, the grade of activity $(A)$, and the stage of fibrosis $(F)$, the latter according to the NASH Clinical Research Network.

Cost, procedure-related complications and intra- and inter-observer variations in reporting the histology are the major draw backs of liver biopsy, and, therefore, it is usually not recommended in clinical practice, except in circumstances where other differential diagnoses are to be excluded.

\section{Treatment of NAFLD}

There is no single intervention that is proven to be fully effective in the treatment and cure of NAFLD. The main goals of treatment are to improve steatosis and to prevent progression of the disease. Intense lifestyle modification and treatment of the risk factors are the cornerstones of disease management. Medical and surgical interventions serve as second-line treatments, or as adjuvants.

\section{Lifestyle interventions}

Sustained and effective weight loss through calorie restriction and increased physical activity have been shown to improve liver function and histology in multiple studies. ${ }^{64,65}$ Both exercise and dietary interventions in isolation or in combination have been shown to improve biochemical and histological parameters of NAFLD. Low-carbohydrate high-fat diet has been shown to be effective in improving all the abnormal clinical and biochemical parameters of metabolic syndrome and NAFLD in multiple studies. ${ }^{66}$ These dietary interventions are also associated with weight loss in patients. Even without significant weight loss, however, lifestyle interventions were found to improve NAFLD, especially if patients are adherent to the changes. ${ }^{67}$ Yet, patient compliance issues always represent a challenge to these interventions.

\section{Insulin sensitizing agents}

Being a disease associated with IR and metabolic syndrome, insulin sensitizing agents are expected to alter the pathophysiological mechanisms of NAFLD. Metformin and the thiazolidinedione group of antidiabetic agents are the most studied medications in this group.

\section{Metformin}

Although metformin use was associated with significant improvements in IR and liver transaminases (AST and ALT), the drug failed to show improvement in the histological parameters, such as steatosis, inflammation, hepatocellular ballooning and fibrosis. ${ }^{68}$ However, because of the 
Pappachan J.M. et al: Non-alcoholic fatty liver disease

antidiabetic efficacy, metformin should be considered for patients with T2DM or even prediabetic states and NAFLD. Metformin is found to be safe, even in patients with cirrhosis, and may protect against development of HCC in cases with T2DM and chronic liver diseases. ${ }^{69}$

\section{Thiazolidinediones}

These drugs modulate tissue insulin sensitivity through the peroxisome proliferator activated receptor (PPAR)- $\gamma$ signalling, and improve blood glucose control. Rosiglitazone and pioglitazone are the agents widely studied in this class of drugs for management of T2DM. Following the controversy about increased cardiovascular events, rosiglitazone use has been much lower in recent years, with pioglitazone being the agent widely used currently. Pioglitazone has been shown to improve the hepatic insulin sensitivity and fatty acid oxidation, and to inhibit hepatic lipogenesis. ${ }^{70}$ There is moderate quality evidence to suggest the benefits of pioglitazone in improvement of biochemical and histological parameters of NAFLD, although the drug use may be associated with weight gain. ${ }^{71,72}$ In combination with intense lifestyle modification, this drug should be considered in patients with NASH.

\section{Antioxidants}

Oxidative stress plays a major role in the pathogenesis of NAFLD and several investigators studied the effects of antioxidants extensively. ${ }^{71-74}$ Vitamin $\mathrm{E}$ is the most studied antioxidant in this group. Supplementation of this was associated with significant improvement in all histological parameters, such as steatosis, hepatocyte ballooning, lobular inflammation and fibrosis, as compared to placebo. ${ }^{73}$ Vitamin $E$ is used in the dose of 800 International Units daily for patients with $\mathrm{NASH}$, especially in non-diabetic cases. ${ }^{1,74}$ Although multiple agents such as $\mathrm{N}$-acetylcysteine, betaine, probucol, viusid, and silibinin (milk thistle) have been used in different trials, the use of these agents are not recommended in current clinical practice because of conflicting/insufficient evidence on the benefits. ${ }^{74}$

\section{Incretin-based therapy}

There are two main groups of incretin-related drugs extensively studied for use in NAFLD, viz., GLP-1 analogues (e.g., exenatide, liraglutide, lixisenatide, dulaglutide and semaglutide) and dipeptidyl peptidase-4 (DPP-4) inhibitors (e.g., sitagliptin, saxagliptin, vildagliptin, alogliptin and linagliptin). Both classes of drugs augment the meal-related insulin secretion from the pancreas, along with extra-pancreatic effects on multiple organs that make them very useful for the management of T2DM. ${ }^{75}$ Use of GLP-1 analogues are associated with weight loss, and DPP-4 inhibitors are weight neutral. Incretin-based therapy is very commonly used in overweight/ obese T2DM patients, many of whom suffer from NAFLD as well. Remarkable benefits of both the conditions make this class of agents unique in managing the cases. ${ }^{20}$

Recent evidence suggests that patients with NASH, particularly those with T2DM, get significant benefits from GLP-1 analogue therapy, with improvement in liver histology and reduction in liver transaminase levels from baseline. ${ }^{76-78}$ In patients with NAFLD/NASH with or without T2DM, the benefits of GLP-1 analogue therapy may outweigh the risk of use, and, therefore, it should be considered. Although less effective,
DPP-4 inhibitors are also reported as effective in patients with NAFLD and T2DM. ${ }^{20,79}$

\section{Lipid lowering agents}

Lipid lowering agents are useful for treatment, especially in patients with concurrent dyslipidaemia and NAFLD. A Cochrane review in 2013 reported possible improvements in serum aminotransferase levels and ultrasonological abnormalities in cases treated with statins, although the studies included in the review were small with high risk of bias. ${ }^{80}$ The review concluded that statins can improve the adverse outcomes related to NASH in patients with concurrent diseases, such as hyperlipidaemia, diabetes mellitus, and metabolic syndrome. A more recent small randomized control trial (RCT) found that rosuvastatin monotherapy could ameliorate biopsy-proven NASH with resolution of metabolic syndrome within 12 months of treatment. ${ }^{81}$ Unfortunately, the potential for complications associated with liver biopsy makes it difficult to perform large RCTs in patients with NASH.

In experimental models of NAFLD, fenofibrate use was also found to reduce liver steatosis associated with high-fat diet, T2DM and metabolic syndrome. ${ }^{82}$ Some small clinical studies also showed beneficial effects. However, small sample sizes and lack of histological data limit the validity of these results. ${ }^{82}$ Multiple RCTs and meta-analyses showed beneficial effects of omega- 3 fatty acids both in adults and children with NAFLD. ${ }^{83-85}$

Proprotein convertase subtilisin/kexin type 9 (PCSK9) is a molecule secreted by hepatocytes that inhibits uptake of LDL by targeting the receptor for degradation, and which augments lipogenesis. ${ }^{86}$ Circulating PCSK9 levels have been found to be elevated in patients with NAFLD. PCSK9 inhibitors have been recently shown to be highly effective in reducing hypercholesterolemia in patients with remarkable improvement of the associated cardiovascular risk. ${ }^{87}$

Because the treatment is expensive, these drugs are often reserved for patients with statin intolerance and familial forms of lipid disorders inadequately managed by full doses of other lipid lowering agents.

\section{Drugs for weight loss}

Medications that help weight loss may potentially alter the pathogenic mechanisms of NAFLD and may be useful in selected patients. Most of these medications are associated with only modest weight loss benefit and several of them have been withdrawn from the market owing to undesirable side effects.

\section{Orlistat}

This medication inhibits pancreatic lipase, resulting in fat malabsorption and weight loss as a consequence. Although two previous RCTs showed some beneficial effects of orlistat in patients with $\mathrm{NASH}$, it is not clear if the benefit was related to weight loss conferred by the drug or direct effect. ${ }^{88-90}$ Therefore, the drug use should be selected for individual patients as per the clinician's discretion and situation.

\section{Lorcaserin}

This is an appetite suppressant associated with about $4 \%$ weight loss in 12 months when combined with lifestyle 
changes. ${ }^{91}$ Pooled data from three lorcaserin RCTs showed that there was modest reduction in ALT levels and improvement of cardiovascular outcomes in treated patients with NAFLD compared to placebo. ${ }^{92}$

\section{Naltrexone/bupropion combination}

This drug combination is associated with a weight loss of approximately $5 \%$. Modest reductions in hepatic aminotransferase levels were observed in patients who lost $>10 \%$ weight in 12 months with higher dose of the combination. ${ }^{93}$

\section{Phentermine/topiramate}

This combination is also associated with significant weight loss benefit and may be associated with improvement of NAFLD. ${ }^{94}$

\section{Liraglutide}

High-dose liraglutide treatment ( $3 \mathrm{mg}$ daily) has been approved by the United States' Food and Drug Administration and the European Medicine Agency recently for primary management of obesity in patients without diabetes. About $8.5 \%$ weight loss has been observed in the treated patients compared to placebo in a major clinical trial, although the data on NAFLD was not available in this study. ${ }^{95}$ However, another recent phase 2 clinical trial reported significant improvement of liver histology when $1.8 \mathrm{mg}$ liraglutide was administered to patients. ${ }^{96}$ Therefore, high-dose liraglutide treatment also may be associated with the same benefit.

\section{Other novel agents}

Pentoxyphylline is a competitive nonselective phosphodiesterase inhibitor which raises cyclic adenosine monophosphate and inhibits tumour necrosis factor- $\alpha$. Both animal studies and clinical trials in humans showed beneficial effects of this novel agent. ${ }^{71,72,97}$ Although prebiotics and probiotics have been claimed to be useful in the treatment and prevention of patients with obesity and NAFLD, inadequate supporting data from high-quality clinical studies is against recommendation of the use of these medications in normal clinical practice. ${ }^{98}$

Obeticholic acid (OCA) is a synthetic bile acid and agonist of farnesoid $X$ receptor (FXR) that has been recently developed for treatment of primary biliary cirrhosis and has shown promise in the management of NAFLD. ${ }^{99}$ FXR is an important nuclear receptor involved in the regulation of bile acid, glucose and cholesterol homeostasis in the human body. ${ }^{94}$ Both animal and human studies showed beneficial effects of OCA in the management of NAFLD. ${ }^{99}$ Another novel agent elafibranor, a PPAR- $\alpha / \delta$ agonist, was shown to improve NASH without fibrosis worsening in patients with moderate or severe NASH compared to placebo in a recent clinical trial. ${ }^{100}$ The drug is well tolerated and yields improved cardiometabolic risk profile in patients.

\section{Bariatric surgery}

Obese patients undergoing bariatric surgery showed significant improvements in both histological and biochemical parameters of NAFLD in a recent meta-analysis. ${ }^{101}$ Histological features of the disease, such as steatosis, fibrosis, hepatocyte ballooning and lobular inflammation, as well as reduction in the liver enzyme levels including ALT, AST, alkaline phosphatase and $\gamma$-glutamyl transferase were observed in patients who underwent surgery. In 2015, based on level B evidence, the Japanese Society of Gastroenterology in cooperation with the Japan Society of Hepatology recommended weight loss surgery as an effective treatment option for patients with NAFLD/NASH complicated by severe obesity for improving fatty changes in the liver and inflammation associated with NASH. ${ }^{102}$

Although there is no clear global consensus from different professional bodies on the indications for recommending metabolic surgery in patients with NAFLD, rapidly emerging evidence may lead us towards such a consensus in near future. The most recently published data from the STAMPDE clinical trial that revealed remarkable improvements in the parameters of metabolic syndrome following bariatric surgery is a good example of such high-quality evidence. ${ }^{103}$

\section{Liver transplantation}

Recent data suggests that NASH-related end-stage liver disease is the third leading cause for hepatic transplants in the United States and is expected to become the most common cause for liver transplant in 1-2 decades because of the obesity epidemic. ${ }^{104}$ The upward global trend in the prevalence of obesity is expected to cause the same health burden in most other regions of the world in the near future. Therefore, liver transplants would become a standard treatment option in a significant proportion of patients with advanced stages of NAFLD.

Based on level B and strength 2 evidence, the Japanese Society of Gastroenterology in association with the Japan Society of Hepatology recommend liver transplant for patients with advanced NASH hepatic failure. ${ }^{102}$ The overall survival rates after hepatic transplantation in these patients are almost identical to those receiving transplants for liver failure from other hepatic disorders. However, almost one-third of patients who receive liver transplant for NASH will have recurrence of the disease in the transplanted liver in the absence of intense post-transplant lifestyle modifications. ${ }^{105,106}$

Table 1. NASH Clinical Research Network histological scoring system

\begin{tabular}{ll}
\hline NAFLD activity score & NASH fibrosis stage \\
\hline Steatosis & Stage $\mathbf{0}$ \\
$<5 \%: 0$ & No fibrosis \\
$5-33 \%: 1$ & \\
$34-66 \%: 2$ & Stage $\mathbf{1}$ \\
$>66 \%: 3$ & Zone $\mathbf{3}$ perisinusoidal fibrosis \\
Lobular & - Mild - 1a \\
inflammation & - Moderate - 1b \\
None: 0 & - Portal/periportal - 1c \\
$<2: 1$ & \\
2-4: 3 & Stage $\mathbf{2}$ \\
$>4: 4$ & Perisinusoidal and portal/ \\
Ballooning of & periportal fibrosis \\
hepatocytes & \\
None: 0 & Stage $\mathbf{3}$ \\
Few ballooned: 1 & Bridging fibrosis \\
Many ballooned: 2 & \\
NAS score $(\mathbf{0}-\mathbf{8})$ & Stage $\mathbf{4}$ \\
$<3:$ not NASH & Cirrhosis \\
$\geq 5:$ NASH & \\
\hline
\end{tabular}


Pappachan J.M. et al: Non-alcoholic fatty liver disease

Table 2. Drug classes, main mode of actions and side effects, and level of evidence for use in clinical practice

\begin{tabular}{|c|c|c|c|c|}
\hline Category of drug & $\begin{array}{l}\text { Representative } \\
\text { drug }\end{array}$ & Main mode of action & $\begin{array}{l}\text { Main/serious } \\
\text { side effects }\end{array}$ & $\begin{array}{l}\text { Evidence for benefit } \\
\text { in NAFLD/NASH }\end{array}$ \\
\hline Biguanide & Metformin & Improved insulin sensitivity & $\begin{array}{l}\text { Gastrointestinal } \\
\text { upset }\end{array}$ & $\begin{array}{l}\text { Recommended in } \\
\text { patients with T2DM and } \\
\text { NAFLD }(1 / \oplus \oplus \oplus O)\end{array}$ \\
\hline Thiazolidinediones & Pioglitazone & $\begin{array}{l}\text { Modulate tissue insulin } \\
\text { sensitivity through PPAR }\end{array}$ & $\begin{array}{l}\text { Worsening heart } \\
\text { failure }\end{array}$ & $\begin{array}{l}\text { Recommended in } \\
\text { patients with NASH and } \\
\text { T2DM }(1 / \oplus \oplus \oplus O)\end{array}$ \\
\hline GLP 1 analogues & Exenatide/liraglutide & $\begin{array}{l}\text { Suppress appetite, helps } \\
\text { weight loss and enhances } \\
\text { endogenous insulin production }\end{array}$ & $\begin{array}{l}\text { Gastrointestinal } \\
\text { upset }\end{array}$ & $\begin{array}{l}\text { Recommended in } \\
\text { obese/overweight T2DM } \\
\text { and NAFLD }(1 / \oplus \oplus \oplus O)\end{array}$ \\
\hline DPP 4 inhibitors & Sitagliptin/linagliptin & $\begin{array}{l}\text { Enhances endogenous insulin } \\
\text { production }\end{array}$ & $\begin{array}{l}\text { Gastrointestinal } \\
\text { upset }\end{array}$ & $\begin{array}{l}\text { Suggested in obese/ } \\
\text { overweight T2DM with } \\
\text { NAFLD }(2 / \oplus \oplus O \bigcirc)\end{array}$ \\
\hline Antioxidants & Vitamin E & Reduces oxidative stress & $\begin{array}{l}\text { Haemorrhagic } \\
\text { stroke }\end{array}$ & $\begin{array}{l}\text { Recommended in } \\
\text { patients with NASH and } \\
\text { without diabetes } \\
(1 / \oplus \oplus \oplus \bigcirc)\end{array}$ \\
\hline $\begin{array}{l}\text { Phosphodiesterase } \\
\text { inhibitor }\end{array}$ & Pentoxyphylline & $\begin{array}{l}\text { Raises C-AMP and reduces } \\
\text { TNF- } \alpha\end{array}$ & $\begin{array}{l}\text { Upper } \\
\text { gastrointestinal } \\
\text { upset }\end{array}$ & $\begin{array}{l}\text { Suggested in NASH } \\
(2 / \oplus \oplus \bigcirc \bigcirc)\end{array}$ \\
\hline Statin & Atorvastatin & Lowers plasma lipids & $\begin{array}{l}\text { Muscle pains } \\
\text { and myopathy }\end{array}$ & $\begin{array}{l}\text { Suggested in patients } \\
\text { with dyslipidaemia \& } \\
\text { NAFLD }(2 / \oplus \oplus \bigcirc \bigcirc)\end{array}$ \\
\hline Lipase inhibitor & Orlistat & $\begin{array}{l}\text { Decreases fat absorption from } \\
\text { intestine and reduces body } \\
\text { weight }\end{array}$ & Diarrhoea & $\begin{array}{l}\text { Suggested in obese } \\
\text { patients }(2 / \oplus \bigcirc \bigcirc \bigcirc)\end{array}$ \\
\hline $\begin{array}{l}\text { Farnesoid XR } \\
\text { agonist }\end{array}$ & Obeticholic acid & $\begin{array}{l}\text { Alters hepatic lipogenesis and } \\
\text { reduces steatosis and } \\
\text { inflammation }\end{array}$ & Pruritus & $\begin{array}{l}\text { Suggested in patients } \\
\text { with NASH }(2 / \oplus \oplus O O)\end{array}$ \\
\hline $\operatorname{PPAR}-\alpha / \delta$ agonist & Elafibranor & $\begin{array}{l}\text { Reduces steatosis, } \\
\text { inflammation and fibrosis }\end{array}$ & $\begin{array}{l}\text { Transient } \\
\text { increase in } \\
\text { serum } \\
\text { creatinine }\end{array}$ & $\begin{array}{l}\text { Suggested in patients } \\
\text { with NASH }(2 / \oplus \oplus O O)\end{array}$ \\
\hline
\end{tabular}

The Grading of Recommendations, Assessment, Development, and Evaluation (GRADE) system is used to describe the strength of recommendations and the quality of evidence. Strong recommendations are denoted by "Recommend" and the number 1 , and weak recommendations by the phrase "Suggested" and the number 2 . Cross-filled circles indicate the quality of the evidence, such that $\oplus \circ \circ \bigcirc$ denotes very low quality evidence, $\oplus \oplus \circ \circ$ denotes low quality, $\oplus \oplus \oplus \circ$ denotes moderate quality, and $\oplus \oplus \oplus \oplus$ denotes high quality.

Table 2 summarizes some of the therapeutic agents available for management of patients with NAFLD/NASH and the level of evidence for the use of these medications.

\section{Conclusions}

There has been an exponential increase in the global incidence and prevalence of NAFLD because of the obesity pandemic. In the absence of therapeutic interventions, significant proportion of cases progress to NASH, with increased morbidity and mortality. Diagnosis of NAFLD often depends on biochemical and radiological investigations, as early stages of the disease are often clinically silent. Management of the disease primarily depends on intense lifestyle changes to lose weight. Insulin sensitizers, antioxidants, incretin-based drugs, lipid lowering agents, weight loss medications, bariatric surgery and liver transplantation are therapeutic options that can be added to lifestyle interventions when necessary for management of cases. Continued research for optimizing management strategies of this common disorder is important for reducing the global burden of NAFLD.

\section{Conflict of interest}

The authors have no conflicts of interests related to this publication.

\section{Author contributions}

Prepared the initial draft (SB, BK), conceived the manuscript plan, and grossly modified the initial draft which had been prepared by (JMP), helped in draft modification and revision of the paper (NCR). All authors contributed to the literature search and writing of the final manuscript. 


\section{References}

[1] Carr RM, Oranu A, Khungar V. Nonalcoholic fatty liver disease: pathophysiology and management. Gastroenterol Clin North Am 2016;45:639-652. doi: $10.1016 / j$.gtc. 2016.07 .003 .

[2] Schwimmer JB, Behling C, Newbury R, Deutsch R, Nievergelt C, Schork NJ, et al. Histopathology of pediatric nonalcoholic fatty liver disease. Hepatology 2005;42:641-649. doi: 10.1002/hep.20842.

[3] Bataller R, Rombouts K, Altamirano J, Marra F. Fibrosis in alcoholic and nonalcoholic steatohepatitis. Best Pract Res Clin Gastroenterol 2011;25: 231-244. doi: 10.1016/j.bpg.2011.02.010.

[4] Adams L. Transient elastography in nonalcoholic fatty liver disease: making sense of echoes. Hepatology 2010;51:370-372. doi: 10.1002/hep.23422.

[5] Browning JD, Szczepaniak LS, Dobbins R, Nuremberg P, Horton JD, Cohen JC, et al. Prevalence of hepatic steatosis in an urban population in the United States: impact of ethnicity. Hepatology 2004;40:1387-1395. doi: 10.1002/ hep. 20466

[6] Jimba S, Nakagami T, Takahashi M, Wakamatsu T, Hirota Y, Iwamoto Y, et al. Prevalence of non-alcoholic fatty liver disease and its association with impaired glucose metabolism in Japanese adults. Diabet Med 2005;22: 1141-1145. doi: 10.1111/j.1464-5491.2005.01582.x.

[7] López-Velázquez JA, Silva-Vidal KV, Ponciano-Rodríguez G, Chávez-Tapia NC, Arrese $M$, Uribe $M$, et al. The prevalence of nonalcoholic fatty liver disease in the Americas. Ann Hepatol 2014;13:166-178.

[8] Sun DQ, Liu WY, Wu SJ, Zhu GQ, Braddock M, Zhang DC, et al. Increased levels of low-density lipoprotein cholesterol within the normal range as a risk factor for nonalcoholic fatty liver disease. Oncotarget 2016;7:5728-5737. doi: 10.18632/oncotarget.6799.

[9] Kabbany MN, Conjeevaram Selvakumar PK, Watt K, Lopez R, Akras Z, Zein N, et al. Prevalence of nonalcoholic steatohepatitis-associated cirrhosis in the United States: an analysis of national health and nutrition examination survey data. Am J Gastroenterol 2017;112:581-587. doi: 10.1038/ajg.2017.5.

[10] Bellentani S, Scaglioni F, Marino M, Bedogni G. Epidemiology of non-alcoholic fatty liver disease. Dig Dis 2010;28:155-161. doi: 10.1159/000282080.

[11] Fazel Y, Koenig AB, Sayiner M, Goodman ZD, Younossi ZM. Epidemiology and natural history of non-alcoholic fatty liver disease. Metabolism 2016 65:1017-1025. doi: 10.1016/j.metabol.2016.01.012.

[12] Calzadilla Bertot $L$, Adams LA. The natural course of non-alcoholic fatty liver disease. Int J Mol Sci 2016;17. pii: E774. doi: 10.3390/ijms17050774.

[13] McPherson S, Hardy T, Henderson E, Burt AD, Day CP, Anstee QM. Evidence of NAFLD progression from steatosis to fibrosing-steatohepatitis using paired biopsies: implications for prognosis and clinical management. J Hepatol 2015;62:1148-1155. doi: 10.1016/j.jhep.2014.11.034

[14] Mahfood Haddad T, Hamdeh S, Kanmanthareddy A, Alla VM. Nonalcoholic fatty liver disease and the risk of clinical cardiovascular events: A systematic review and meta-analysis. Diabetes Metab Syndr 2016. doi: 10.1016/ j.dsx.2016.12.033.

[15] Sanyal AJ, Friedman SL, McCullough AJ, Dimick-Santos L. American Association for the Study of Liver Diseases; United States Food and Drug Administration. Challenges and opportunities in drug and biomarker development for nonalcoholic steatohepatitis: findings and recommendations from an American Association for the Study of Liver Diseases-U.S. Food and Drug Administration Joint Workshop. Hepatology 2015;61:1392-1405. doi: 10. 1002/hep. 27678.

[16] Rinella ME. Nonalcoholic fatty liver disease: a systematic review. JAMA 2015;313:2263-2273. doi: 10.1001/jama.2015.5370

[17] Reeves HL, Zaki MY, Day CP. Hepatocellular carcinoma in obesity, type 2 diabetes, and NAFLD. Dig Dis Sci 2016;61:1234-1245. doi: 10.1007/ s10620-016-4085-6.

[18] Severson TJ, Besur S, Bonkovsky HL. Genetic factors that affect nonalcoholic fatty liver disease: A systematic clinical review. World J Gastroenterol 2016;22:6742-6756. doi: 10.3748/wjg.v22.i29.6742.

[19] Adams LA, Sanderson S, Lindor KD, Angulo P. The histological course of nonalcoholic fatty liver disease: a longitudinal study of 103 patients with sequential liver biopsies. J Hepatol 2005;42:132-138. doi: 10.1016/j.jhep. 2004.09.012.

[20] Pappachan JM, Antonio FA, Edavalath M, Mukherjee A. Non-alcoholic fatty liver disease: a diabetologist's perspective. Endocrine 2014;45:344-353. doi: 10.1007/s12020-013-0087-8.

[21] Loria P, Lonardo A, Anania F. Liver and diabetes. A vicious circle. Hepatol Res 2013:43:51-64 doi: 10.1111/j.1872-034X.2012.01031.x

[22] Petta S, Gastaldelli A, Rebelos E, Bugianesi E, Messa P, Miele L, et al. Pathophysiology of non alcoholic fatty liver disease. Int J Mol Sci 2016;1712: 2082. doi: 10.3390/ijms17122082.

[23] Bugianesi E, Pagotto U, Manini R, Vanni E, Gastaldelli A, de Iasio R, et al. Plasma adiponectin in nonalcoholic fatty liver is related to hepatic insulin resistance and hepatic fat content, not to liver disease severity. J Clin Endocrinol Metab 2005;90:3498-3504. doi: 10.1210/jc.2004-2240.
[24] Polyzos SA, Aronis KN, Kountouras J, Raptis DD, Vasiloglou MF, Mantzoros CS. Circulating leptin in non-alcoholic fatty liver disease: a systematic review and meta-analysis. Diabetologia 2016;59:30-43. doi: 10.1007/ s00125-015-3769-3.

[25] Mittendorfer B, Yoshino M, Patterson BW, Klein S. VLDL triglyceride kinetics in lean, overweight, and obese men and women. J Clin Endocrinol Metab 2016;101:4151-4160. doi: 10.1210/jc.2016-1500.

[26] Seto WK, Yuen MF. Nonalcoholic fatty liver disease in Asia: emerging perspectives. J Gastroenterol 2017;52:164-174. doi: 10.1007/s00535-0161264-3.

[27] Kim D, Kim WR. Nonobese fatty liver disease. Clin Gastroenterol Hepatol 2017;15:474-485. doi: 10.1016/j.cgh.2016.08.028.

[28] Feldman A, Eder SK, Felder TK, Kedenko L, Paulweber B, Stadlmayr A, et al. Clinical and metabolic characterization of lean caucasian subjects with non-alcoholic fatty liver. Am J Gastroenterol 2017;112:102-110. doi: 10. 1038/ajg.2016.318.

[29] Pedersen BK, Febbraio MA. Muscles, exercise and obesity: skeletal muscle as a secretory organ. Nat Rev Endocrinol 2012;8:457-465. doi: 10.1038/ nrendo.2012.49.

[30] Arias-Loste MT, Ranchal I, Romero-Gómez M, Crespo J. Irisin, a link among fatty liver disease, physical inactivity and insulin resistance. Int J Mol Sci 2014;15:23163-23178. doi: 10.3390/ijms151223163.

[31] Boström P, Wu J, Jedrychowski MP, Korde A, Ye L, Lo JC, et al. A PGC1$\alpha$-dependent myokine that drives brown-fat-like development of white fat and thermogenesis. Nature 2012;481:463-468. doi: 10.1038/nature10777.

[32] Choi ES, Kim MK, Song MK, Kim JM, Kim ES, Chung WJ, et al. Association between serum irisin levels and non-alcoholic fatty liver disease in health screen examinees. PLoS One 2014;9:e110680. doi: 10.1371/journal.pone. 0110680.

[33] Rizk FH, Elshweikh SA, Abd El-Naby AY. Irisin levels in relation to metabolic and liver functions in Egyptian patients with metabolic syndrome. Can J Physiol Pharmacol 2016;94:359-362. doi: 10.1139/cjpp-2015-0371.

[34] Huh JY, Panagiotou G, Mougios V, Brinkoetter M, Vamvini MT, Schneider BE, et al. FNDC5 and irisin in humans: I. Predictors of circulating concentrations in serum and plasma and II. mRNA expression and circulating concentrations in response to weight loss and exercise. Metabolism 2012;61: 1725-1738. doi: 10.1016/j.metabol.2012.09.002

[35] Sanchis-Gomar F, Lippi G, Mayero S, Perez-Quilis C, García-Giménez JL. Irisin: a new potential hormonal target for the treatment of obesity and type 2 diabetes. J Diabetes 2012;4:196. doi: 10.1111/j.1753-0407.2012. 00194.x.

[36] Turnbaugh PJ, Ley RE, Mahowald MA, Magrini V, Mardis ER, Gordon JI. An obesity-associated gut microbiome with increased capacity for energy harvest. Nature 2006;444:1027-1031. doi: 10.1038/nature05414.

[37] Abu-Shanab A, Quigley EM. The role of the gut microbiota in nonalcoholic fatty liver disease. Nat Rev Gastroenterol Hepatol 2010;7:691-701. doi: 10.1038 /nrgastro.2010.172.

[38] Henao-Mejia J, Elinav E, Jin C, Hao L, Mehal WZ, Strowig T, et al. Inflammasome-mediated dysbiosis regulates progression of NAFLD and obesity. Nature 2012;482:179-185. doi: 10.1038/nature10809.

[39] Zhu L, Baker SS, Gill C, Liu W, Alkhouri R, Baker RD, et al. Characterization of gut microbiomes in nonalcoholic steatohepatitis (NASH) patients: a connection between endogenous alcohol and NASH. Hepatology 2013;57:601-609. doi: 10.1002/hep.26093.

[40] Schnabl B, Brenner DA. Interactions between the intestinal microbiome and liver diseases. Gastroenterology 2014;146:1513-1524. doi: 10.1053/j. gastro.2014.01.020

[41] Boursier J, Mueller O, Barret M, Machado M, Fizanne L, Araujo-Perez F, et al. The severity of nonalcoholic fatty liver disease is associated with gut dysbiosis and shift in the metabolic function of the gut microbiota. Hepatology 2016;63:764-775. doi: 10.1002/hep.28356.

[42] Luther J, Garber J], Khalili H, Dave M, Bale SS, Jindal R, et al. Hepatic injury in nonalcoholic steatohepatitis contributes to altered intestinal permeability. Cell Mol Gastroenterol Hepatol 2015;1:222-232. doi: 10.1016/j.jcmgh. 2015.01 .001$.

[43] Dixon LJ, Berk M, Thapaliya S, Papouchado BG, Feldstein AE. Caspase-1mediated regulation of fibrogenesis in diet-induced steatohepatitis. Lab Invest 2012;92:713-723. doi: 10.1038/labinvest.2012.45.

[44] Dixon LJ, Barnes M, Tang H, Pritchard MT, Nagy LE. Kupffer cells in the liver. Compr Physiol 2013;3:785-797. doi: 10.1002/cphy.c120026.

[45] Kimura I, Ozawa K, Inoue D, Imamura T, Kimura K, Maeda T, et al. The gut microbiota suppresses insulin-mediated fat accumulation via the short-chain fatty acid receptor GPR43. Nat Commun 2013;4:1829. doi: 10.1038/ ncomms2852.

[46] Ridaura VK, Faith J], Rey FE, Cheng J, Duncan AE, Kau AL, et al. Gut microbiota from twins discordant for obesity modulate metabolism in mice. Science 2013;341:1241214. doi: 10.1126/science.1241214.

[47] Volynets V, Küper MA, Strahl S, Maier IB, Spruss A, Wagnerberger S, et al. Nutrition, intestinal permeability, and blood ethanol levels are altered in 
patients with nonalcoholic fatty liver disease (NAFLD). Dig Dis Sci 2012;57: 1932-1941. doi: 10.1007/s10620-012-2112-9.

[48] European Association for the Study of the Liver (EASL); European Association for the Study of Diabetes (EASD); European Association for the Study of Obesity (EASO). EASL-EASD-EASO Clinical Practice Guidelines for the management of non-alcoholic fatty liver disease. J Hepatol 2016;64: 1388-1402. doi: 10.1016/j.jhep.2015.11.004

[49] Marchesini G, Petta S, Dalle Grave R. Diet, weight loss, and liver health in nonalcoholic fatty liver disease: Pathophysiology, evidence, and practice. Hepatology 2016;63:2032-2043. doi: 10.1002/hep.28392.

[50] Fracanzani AL, Valenti L, Bugianesi E, Andreoletti M, Colli A, Vanni E, et al. Risk of severe liver disease in nonalcoholic fatty liver disease with normal aminotransferase levels: a role for insulin resistance and diabetes. Hepatology 2008;48:792-798. doi: 10.1002/hep.22429.

[51] Verma S, Jensen D, Hart J, Mohanty SR. Predictive value of ALT levels for non-alcoholic steatohepatitis (NASH) and advanced fibrosis in non-alcoholic fatty liver disease (NAFLD). Liver Int 2013;33:1398-1405. doi: 10.1111/ liv. 12226.

[52] Oh H, Jun DW, Saeed WK, Nguyen MH. Non-alcoholic fatty liver diseases: update on the challenge of diagnosis and treatment. Clin Mol Hepatol 2016; 22:327-335. doi: 10.3350/cmh.2016.0049.

[53] Angulo P, Hui JM, Marchesini G, Bugianesi E, George J, Farrell GC, et al. The NAFLD fibrosis score: a noninvasive system that identifies liver fibrosis in patients with NAFLD. Hepatology 2007;45:846-854. doi: 10.1002/hep. 21496.

[54] Jun DW, Kim SG, Park SH, Jin SY, Lee JS, Lee JW, et al. External validation of the non-alcoholic fatty liver disease fibrosis score for assessing advanced fibrosis in Korean patients. J Gastroenterol Hepatol 2017;32:1094-1099. doi: 10.1111/jgh.13648.

[55] Lee JY, Kim KM, Lee SG, Yu E, Lim YS, Lee HC, et al. Prevalence and risk factors of non-alcoholic fatty liver disease in potential living liver donors in Korea: a review of 589 consecutive liver biopsies in a single center. J Hepatol 2007;47:239-244. doi: 10.1016/j.jhep.2007.02.007.

[56] Khov N, Sharma A, Riley TR. Bedside ultrasound in the diagnosis of nonalcoholic fatty liver disease. World J Gastroenterol 2014;20:6821-6825. doi: $10.3748 /$ wjg.v20.i22.6821.

[57] Kwok R, Tse YK, Wong GL, Ha Y, Lee AU, Ngu MC, et al. Systematic review with meta-analysis: non-invasive assessment of non-alcoholic fatty liver disease-the role of transient elastography and plasma cytokeratin-18 fragments. Aliment Pharmacol Ther 2014;39:254-269. doi: 10.1111/apt. 12569.

[58] Karlas T, Petroff $D$, Sasso M, Fan JG, Mi YQ, de Lédinghen $V$, et al. Individua patient data meta-analysis of controlled attenuation parameter (CAP) technology for assessing steatosis. J Hepatol 2017;66:1022-1030. doi: 10. 1016/j.jhep.2016.12.022.

[59] Kinner S, Reeder SB, Yokoo T. Quantitative imaging biomarkers of NAFLD. Dig Dis Sci 2016;61:1337-1347. doi: 10.1007/s10620-016-4037-1.

[60] Kleiner DE, Brunt EM, Van Natta M, Behling C, Contos MJ, Cummings OW, et al. Design and validation of a histological scoring system for nonalcoholic fatty liver disease. Hepatology 2005;41:1313-1321. doi: 10.1002/hep. 20701.

[61] Brunt EM, Kleiner DE, Wilson LA, Belt P, Neuschwander-Tetri BA; NASH Clinical Research Network (CRN). Nonalcoholic fatty liver disease (NAFLD) activity score and the histopathologic diagnosis in NAFLD: distinct clinicopathologic meanings. Hepatology 2011;53:810-820. doi: 10.1002/hep. 24127.

[62] Brunt EM, Kleiner DE, Behling C, Contos MJ, Cummings OW, Ferrell LD, et al. Misuse of scoring systems. Hepatology 2011;54:369-370; author reply 370-371. doi: 10.1002/hep.24347.

[63] Munteanu M, Tiniakos D, Anstee Q, Charlotte F, Marchesini G, Bugianesi E, et al. Diagnostic performance of FibroTest, SteatoTest and ActiTest in patients with NAFLD using the SAF score as histological reference. Aliment Pharmacol Ther 2016;44:877-889. doi: 10.1111/apt.13770.

[64] Golabi P, Locklear CT, Austin P, Afdhal S, Byrns M, Gerber L, et al. Effectiveness of exercise in hepatic fat mobilization in non-alcoholic fatty live disease: Systematic review. World J Gastroenterol 2016;22:6318-6327. doi: $10.3748 /$ wjg.v22.i27.6318.

[65] Katsagoni CN, Georgoulis M, Papatheodoridis GV, Panagiotakos DB, Kontogianni MD. Effects of lifestyle interventions on clinical characteristics of patients with non-alcoholic fatty liver disease: A meta-analysis. Metabolism 2017;68:119-132. doi: 10.1016/j.metabol.2016.12.006.

[66] Noakes TD, Windt J. Evidence that supports the prescription of lowcarbohydrate high-fat diets: a narrative review. Br J Sports Med 2017;51: 133-139. doi: 10.1136/bjsports-2016-096491.

[67] Nseir W, Hellou E, Assy N. Role of diet and lifestyle changes in nonalcoholic fatty liver disease. World J Gastroenterol 2014;20:9338-9344. doi: 10. 3748/wjg.v20.i28.9338.

[68] Li Y, Liu L, Wang B, Wang J, Chen D. Metformin in non-alcoholic fatty liver disease: A systematic review and meta-analysis. Biomed Rep 2013;1:57-64. doi: $10.3892 / b r .2012 .18$.
[69] Bhat A, Sebastiani G, Bhat M. Systematic review: Preventive and therapeutic applications of metformin in liver disease. World J Hepatol 2015;7: 1652-1659. doi: 10.4254/wjh.v7.i12.1652.

[70] Belfort R, Harrison SA, Brown K, Darland C, Finch J, Hardies ], et al. A placebocontrolled trial of pioglitazone in subjects with nonalcoholic steatohepatitis. N Engl J Med 2006;355:2297-2307. doi: 10.1056/NEJMoa060326.

[71] Singh S, Khera R, Allen AM, Murad MH, Loomba R. Comparative effectiveness of pharmacological interventions for nonalcoholic steatohepatitis: A systematic review and network meta-analysis. Hepatology 2015;62: 1417-1432. doi: 10.1002/hep.27999.

[72] He L, Liu X, Wang L, Yang Z. Thiazolidinediones for nonalcoholic steatohepatitis: A meta-analysis of randomized clinical trials. Medicine (Baltimore) 2016;95:e4947. doi: 10.1097/MD.0000000000004947.

[73] Xu R, Tao A, Zhang S, Deng Y, Chen G. Association between vitamin E and non-alcoholic steatohepatitis: a meta-analysis. Int J Clin Exp Med 2015;8: 3924-3934.

[74] Korean Association for the Study of the Liver (KASL). KASL clinical practice guidelines: management of nonalcoholic fatty liver disease. Clin Mol Hepatol 2013;19:325-348. doi: 10.3350/cmh.2013.19.4.325.

[75] Pappachan JM, Raveendran AV, Sriraman R. Incretin manipulation in diabetes management. World J Diabetes 2015;6:774-781. doi: 10.4239/wjd.v6. i6.774.

[76] Carbone L], Angus PW, Yeomans ND. Incretin-based therapies for the treatment of non-alcoholic fatty liver disease: A systematic review and metaanalysis. J Gastroenterol Hepatol 2016;31:23-31. doi: 10.1111/jgh. 13026.

[77] Tang W, Xu Q, Hong T, Tong G, Feng W, Shen S, et al. Comparative efficacy of anti-diabetic agents on nonalcoholic fatty liver disease in patients with type 2 diabetes mellitus: a systematic review and meta-analysis of randomized and non-randomized studies. Diabetes Metab Res Rev 2016;32:200-216. doi: $10.1002 / d m r r .2713$

[78] Dong Y, Lv Q, Li S, Wu Y, Li L, Li J, et al. Efficacy and safety of glucagon-like peptide-1 receptor agonists in non-alcoholic fatty liver disease: A systematic review and meta-analysis. Clin Res Hepatol Gastroenterol 2017;41: 284-295. doi: 10.1016/j.clinre.2016.11.009.

[79] Nakouti T, Karagiannis AK, Tziomalos K, Cholongitas E. Incretin-based antidiabetic agents for the management of non-alcoholic fatty liver disease. Curr Vasc Pharmacol 2015;13:649-657. doi: 10.2174/ 1570161112666141121112612

[80] Eslami L, Merat S, Malekzadeh R, Nasseri-Moghaddam S, Aramin H. Statins for non-alcoholic fatty liver disease and non-alcoholic steatohepatitis. Cochrane Database Syst Rev 2013:CD008623. doi: 10.1002/14651858. CD008623.pub2.

[81] Kargiotis K, Athyros VG, Giouleme O, Katsiki N, Katsiki E, Anagnostis P, et al. Resolution of non-alcoholic steatohepatitis by rosuvastatin monotherapy in patients with metabolic syndrome. World J Gastroenterol 2015;21:78607868. doi: $10.3748 / w j g . v 21 . i 25.7860$.

[82] Kostapanos MS, Kei A, Elisaf MS. Current role of fenofibrate in the prevention and management of non-alcoholic fatty liver disease. World J Hepato 2013;5:470-478. doi: 10.4254/wjh.v5.i9.470.

[83] Chen LH, Wang YF, Xu QH, Chen SS. Omega-3 fatty acids as a treatment for non-alcoholic fatty liver disease in children: A systematic review and metaanalysis of randomized controlled trials. Clin Nutr 2016. doi: 10.1016/j. clnu.2016.12.009.

[84] He XX, Wu XL, Chen RP, Chen C, Liu XG, Wu BJ, et al. Effectiveness of omega-3 polyunsaturated fatty acids in non-alcoholic fatty liver disease: $a$ meta-analysis of randomized controlled trials. PLoS One 2016;11: e0162368. doi: 10.1371/journal.pone.0162368.

[85] Lu W, Li S, Li J, Wang J, Zhang R, Zhou Y, et al. Effects of omega-3 fatty acid in nonalcoholic fatty liver disease: a meta-analysis. Gastroenterol Res Pract. 2016;2016:1459790. doi: 10.1155/2016/1459790.

[86] Ruscica M, Ferri N, Macchi C, Meroni M, Lanti C, Ricci C, et al. Liver fat accumulation is associated with circulating PCSK9. Ann Med 2016;48: 384-391. doi: 10.1080/07853890.2016.1188328

[87] Lipinski MJ, Benedetto U, Escarcega RO, Biondi-Zoccai G, Lhermusier T Baker NC, et al. The impact of proprotein convertase subtilisin-kexin type 9 serine protease inhibitors on lipid levels and outcomes in patients with primary hypercholesterolaemia: a network meta-analysis. Eur Heart ] /source> 2016;37:536-545. doi: 10.1093/eurheartj/ehv563.

[88] Zelber-Sagi S, Kessler A, Brazowsky E, Webb M, Lurie Y, Santo M, et al. A double-blind randomized placebo-controlled trial of orlistat for the treatment of nonalcoholic fatty liver disease. Clin Gastroenterol Hepatol 2006;4: 639-644. doi: 10.1016/j.cgh.2006.02.004.

[89] Harrison SA, Fecht W, Brunt EM, Neuschwander-Tetri BA. Orlistat for overweight subjects with nonalcoholic steatohepatitis: A randomized, prospective trial. Hepatology 2009;49:80-86. doi: 10.1002/hep.22575.

[90] Younossi ZM, Reyes MJ, Mishra A, Mehta R, Henry L. Systematic review with meta-analysis: non-alcoholic steatohepatitis - a case for personalised treatment based on pathogenic targets. Aliment Pharmacol Ther 2014;39:3-14. doi: 10.1111/apt.12543. 
[91] Apovian CM, Aronne LJ, Bessesen DH, McDonnell ME, Murad MH, Pagotto U et al. Pharmacological management of obesity: an endocrine Society clinical practice guideline. J Clin Endocrinol Metab 2015;100:342-362. doi: 10. 1210/jc.2014-3415.

[92] Mehal WZ, Fain R, Glicklich A, Li Y, Shanahan W, Soliman W. Lorcaserin improves the NASH clinical score in the majority of high-risk patients: a retrospective analysis of three phase 3 studies. Hepatology 2014;60:427A

[93] Winokur A, Halseth A, Dybala $C$, Lam H, Chen S, Chalasani N. Naltrexone/ Bupropion Extended-Release $32 \mathrm{mg} / 360 \mathrm{mg}$ significantly improves liver enzymes in obese/overweight individuals with elevated liver enzymes. Hepatology 2015;62:1268A.

[94] Barb D, Portillo-Sanchez P, Cusi K. Pharmacological management of nonalcoholic fatty liver disease. Metabolism 2016;65:1183-1195. doi: 10.1016/j.metabol.2016.04.004.

[95] Pi-Sunyer X, Astrup A, Fujioka K, Greenway F, Halpern A, Krempf M, et al. A randomized, controlled trial of $3.0 \mathrm{mg}$ of liraglutide in weight management. N Engl J Med 2015;373:11-22. doi: 10.1056/NEJMoa1411892.

[96] Armstrong MJ, Gaunt P, Aithal GP, Barton D, Hull D, Parker R, et al. Liraglutide safety and efficacy in patients with non-alcoholic steatohepatitis (LEAN): a multicentre, double-blind, randomised, placebo-controlled phase 2 study. Lancet 2016;387:679-690. doi: 10.1016/S0140-6736(15) 00803-X.

[97] Ye JH, Chao J, Chang ML, Peng WH, Cheng HY, Liao JW, et al. Pentoxifylline ameliorates non-alcoholic fatty liver disease in hyperglycaemic and dyslipidaemic mice by upregulating fatty acid $\beta$-oxidation. Sci Rep 2016;6:33102. doi: $10.1038 /$ srep33102.

[98] Tarantino G, Finelli C. Systematic review on intervention with prebiotics/ probiotics in patients with obesity-related nonalcoholic fatty liver disease. Future Microbiol 2015;10:889-902. doi: 10.2217/fmb.15.13.
[99] Makri E, Cholongitas E, Tziomalos K. Emerging role of obeticholic acid in the management of nonalcoholic fatty liver disease. World J Gastroenterol 2016;22:9039-9043. doi: 10.3748/wjg.v22.i41.9039.

[100] Ratziu V, Harrison SA, Francque S, Bedossa P, Lehert P, Serfaty $L$, et al. Elafibranor, an agonist of the peroxisome proliferator-activated receptor- $\alpha$ and $-\delta$, induces resolution of nonalcoholic steatohepatitis without fibrosis worsening. Gastroenterology 2016;150:1147-1159.e5. doi: 10.1053/j. gastro.2016.01.038.

[101] Bower G, Toma T, Harling L, Jiao LR, Efthimiou E, Darzi A, et al. Bariatric surgery and non-alcoholic fatty liver disease: a systematic review of liver biochemistry and histology. Obes Surg 2015;25:2280-2289. doi: 10.1007/ s11695-015-1691-x.

[102] Watanabe $S$, Hashimoto $E$, Ikejima $K$, Uto $H$, Ono $M$, Sumida $Y$, et al. Evidence-based clinical practice guidelines for nonalcoholic fatty liver disease/nonalcoholic steatohepatitis. J Gastroenterol 2015;50:364-377. doi: 10.1007/s00535-015-1050-7.

[103] Schauer PR, Bhatt DL, Kirwan JP, Wolski K, Aminian A, Brethauer SA, et al. Bariatric surgery versus intensive medical therapy for diabetes -5-year outcomes. N Engl J Med 2017;376:641-651. doi: 10.1056/NEJMoa1600869.

[104] Charlton M. Evolving aspects of liver transplantation for nonalcoholic steatohepatitis. Curr Opin Organ Transplant 2013;18:251-258. doi: 10. 1097/MOT.0b013e3283615d30.

[105] Canbay A, Sowa JP, Syn WK, Treckmann J. NASH cirrhosis - the new burden in liver transplantation: how should it be managed? Visc Med 2016;32: 234-238. doi: 10.1159/000446379.

[106] Bhagat V, Mindikoglu AL, Nudo CG, Schiff ER, Tzakis A, Regev A. Outcomes of liver transplantation in patients with cirrhosis due to nonalcoholic steatohepatitis versus patients with cirrhosis due to alcoholic liver disease. Liver Transpl 2009;15:1814-1820. doi: 10.1002/It.21927. 